NBER WORKING PAPER SERIES

\title{
USING AUDIT STUDIES TO TEST FOR PHYSICIAN INDUCED DEMAND: THE CASE OF ANTIBIOTIC ABUSE IN CHINA
}

\author{
Janet Currie \\ Wanchuan Lin \\ Juanjuan Meng \\ Working Paper 18153 \\ http://www.nber.org/papers/w18153
}

\author{
NATIONAL BUREAU OF ECONOMIC RESEARCH \\ 1050 Massachusetts Avenue \\ Cambridge, MA 02138 \\ June 2012
}

We thank Ge Zhang, Hao Zhao and Xu Zhang for their research assistance. All errors are ours. Lin acknowledges research support from the Natural Science Foundation of China (No. 70903003 and No. 71073002). The views expressed herein are those of the authors and do not necessarily reflect the views of the National Bureau of Economic Research.

NBER working papers are circulated for discussion and comment purposes. They have not been peerreviewed or been subject to the review by the NBER Board of Directors that accompanies official NBER publications.

(C) 2012 by Janet Currie, Wanchuan Lin, and Juanjuan Meng. All rights reserved. Short sections of text, not to exceed two paragraphs, may be quoted without explicit permission provided that full credit, including (O) notice, is given to the source. 
Using Audit Studies to Test for Physician Induced Demand: The Case of Antibiotic Abuse in China

Janet Currie, Wanchuan Lin, and Juanjuan Meng

NBER Working Paper No. 18153

June 2012

JEL No. I11

\section{$\underline{\text { ABSTRACT }}$}

The overuse of medical services including antibiotics is often blamed on Physician Induced Demand. But since this theory is about physician motivations, it is difficult to test. We conduct an audit study in which physician financial incentives, beliefs about what patients want, and desires to reciprocate for a small gift are systematically varied. We find that all of these treatments reduce antibiotics prescriptions, suggesting that antibiotics abuse in China is not driven by patients actively demanding antibiotics, by physicians believing that patients want antibiotics, or by physicians believing that antibiotics are in the best interests of their patients, but is largely driven by financial incentives. Our results also show that physician behavior can be significantly influenced by the receipt of a token gift, such as a pen.

Janet Currie

Princeton University

316 Wallace Hall

Princeton, NJ 08544

and NBER

jcurrie@ princeton.edu

Wanchuan Lin

Department of Applied Economics

Guanghua School of Management

Peking University

Rm. 325, Hall 2

Beijing 100871, China

wanchuan@gmail.com
Juanjuan Meng

Department of Applied Economics

Guanghua School of Management

Rm. 323, Hall 2

Peking University

Beijing 100871, China

jumeng@gsm.pku.edu.cn 


\section{INTRODUCTION}

A large literature recognizes the fact that physicians often have strong incentives to sell unnecessary services to patients. Antibiotics may be particularly ripe for demand inducement because it is difficult for the patients to know for certain whether they are needed or not, and they are unlikely to inflict harm on most patients (Dranove, 1988).

Yet, it has proven remarkably difficult to test models of "physician induced demand" empirically. For example, one strand of the literature focuses on the fact that areas with, for example, many heart surgeons, often have high rates of heart surgery. However Dranove and Wehner (1994) show that areas with more obstetricians have more child births even though this is unlikely to represent a causal relationship.

More generally, it is difficult to separate the demand and the supply side. Overuse of medical procedures or drugs could reflect consumer demand, doctor beliefs about what consumers want, or erroneous beliefs about what is best for patients. Similarly, changes in physician fees can affect demand as well as supply, given that most patients face copayments (Heaton and Helland, 2009).

This paper uses an audit study to try to identify the reasons for high rates of antibiotic prescription in China. According to some estimates, $90 \%$ of inpatients and $80 \%$ of outpatients are prescribed antibiotics compared to rates of $30 \%$ of inpatients and $20 \%$ of outpatients in the West. ${ }^{1}$ A recent study of 230,800 outpatient prescriptions in twenty eight Chinese cities found that nearly half the prescriptions

${ }^{1}$ Du Wenmin, Vice Director of the Shanghai Clinical Center for Drug Adverse Reaction Monitoring, quoted in the Shanghai Daily, Dec. 17, 2010. 
written between 2007 and 2009 were for antibiotics and that 10 percent were for two or more antibiotics. Antibiotics were prescribed twice as frequently as recommended by the World Health Organization. The authors note however, that their "study provided little insight into the cause or possible solutions," (Li et al., 2012 pg. 1079).

One of the most dangerous potential consequences of rampant antibiotic abuse is that it will encourage the rise of antibiotic-resistant "superbugs" and threaten global health. Antibiotic resistance already appears to be higher in China than in Western countries, and there has been an alarming growth in the prevalence of resistant bacteria (Zhang et al., 2006). Resistant bacteria create increase medical expenditures and can lead to death from uncontrolled infections (Phelps, 1989; Yao and Yang, 2008). Antibiotic abuse also increases the risk of adverse drug reactions (Shehab et al. 2008; James et al. 2011).

The debate about the causes of antibiotic abuse in China mirrors the Physician-Induced Demand literature more generally. Doctors have strong financial incentives to prescribe antibiotics, which are described further below. At the same time commentators argue that patients view antibiotics as a panacea, and demand them even when they are unlikely to be effective (Cars and Hakansson, 1995; Sun et al., 2009). Patients may also demand newer, stronger, antibiotics, perceiving them to be more efficacious, or they may fail to follow dosage instructions (Bi et al., 2000). If patients expect antibiotics, and doctors are pressed for time, then doctors may find it easier to write a prescription than to explain to the patient why it is not necessary 
(Schwartz et al, 1998). Moreover, if doctors believe that patients want antibiotics, then they may prescribe them in order to satisfy their patients (Bennett, 2010). Finally, some physicians may overprescribe antibiotics because they lack professional knowledge about proper antibiotic usage (Yao and Yang, 2008; Sun et al., 2009; Dar-Odeh et al., 2010).

Our audit study was designed to distinguish between these competing explanations. We trained students to act as simulated patients with identical mild flu-like complaints which did not warrant antibiotics prescription and sent teams of five well-matched simulated patients to each audited hospital. We considered one student to be the "control" and the remaining four "treatment" students all deviated from the baseline script in a specific way.

We had three types of treatments: In the first, the patient offered the doctor a small gift at the beginning of the visit. Theories of gift exchange suggest that recipients will seek to reciprocate. Hence, we expect that doctors in this treatment will be more likely to prescribe antibiotics if they believe that is what patients seek. Otherwise, and assuming that they are aware of proper antibiotics use, they should be less likely to prescribe antibiotics since unnecessary prescriptions impose significant financial costs on patients and are inappropriate. The second treatment involved signaling that the patient had knowledge of appropriate antibiotic use and did not wish to take them unnecessarily, while the third eliminated the financial incentive to prescribe by indicating that the patient would purchase any drugs elsewhere. A fourth treatment combined the second and third treatments. 
All of these treatments reduce antibiotics prescription. Gift giving reduced the antibiotic prescription rate by 13.3 percentage points from a baseline of $63.3 \%$, and reduced expenditures by 21.8 RMB from an average of 104.7 RMB (One RMB was equal to approximately 0.16 \$U.S. in January 2012). It also improved service quality. The elimination of the financial incentive to prescribe had by far the largest effect: Informing the doctor that the patient will buy elsewhere reduces the antibiotic prescription rate by 51.6 percentage points from the baseline, a reduction of $82 \%$. Moreover, doctors are much less likely to prescribe powerful Grade 2 antibiotics rather than cheaper Grade 1 antibiotics in this treatment. However, service was significantly worse.

The patient's display of knowledge reduced the antibiotic prescription rate by 20 percentage points, and reduced expenditures by $33.6 \mathrm{RMB}$. It also eliminated the unnecessary prescription of Grade 2 antibiotics. Finally, the treatment combining a display of knowledge with the removal of financial incentives to prescribe had an effect that was only slightly greater than the removal of the financial incentive alone: the antibiotic prescription rate fell by 55.0 percentage points, and expenditures fell by

\subsection{RMB.}

Our paper suggests that antibiotic abuse in China is not driven by patients actively demanding antibiotics, by doctors believing that patients want antibiotics, or by doctors mistakenly believing that antibiotic prescription is in the best interests of their patients, but is largely driven by financial incentives. More generally, our results demonstrate the power of the experimental audit study to test complex theories 
such as the "physician induced demand" hypothesis. Finally, our results suggest that physician behavior can be significantly affected by the offer of a token gift, a finding relevant to the controversy over the appropriateness of gifts to physicians.

The rest of the paper is organized as follows: Section II provides some background information, Section III describes the study design, Section IV explains the empirical model, Section V presents the results of the study, and Section VI marks the conclusion.

\section{BACKGROUND}

In this section, we provide background on medical care in China and the physician induced demand literature, and offer a brief survey of the literature on gifts that inspired one of our experimental treatments. We also provide some discussion of the advantages and disadvantages of our audit study methodology.

\section{Outpatient Medical Care in China}

Chinese hospitals and physicians have substantial monetary incentives to prescribe medications. The equivalent of a U.S. primary care physician does not really exist, so a visit to a hospital or clinic is often the counterpart to a visit to a physician's office in the U.S. (Hsiao and Liu, 1996; Yip et al. 1998; Hew, 2006; Eggleston et al. 2008b). Patients generally purchase drugs at hospitals as well. The central government sets hospital fees at a low level, and historically provided direct transfers to hospitals to cover operating expenses (Hsiao, 1996; Eggleston et al., 2008a). Starting in the early 1980s, the government began decreasing financial support to hospitals but did not allow them to increase fees (Yip and Hsiao, 2008). 
Hence, revenues from drug sales have become more important to hospitals over time. Hospitals are allowed to add a 15\% markup to drug sales (Liu et al., 2000; Eggleston and Yip, 2004; Yip and Hsiao, 2008) and drug sales now account for over 50\% of all hospital revenues, with antibiotics accounting for $47 \%$ of all drug sales (Chen, 2005; Gong, 2009). While doctors are generally salaried employees, their performance bonuses often depend on the volume of revenues generated (Tang et al., 2007). ${ }^{2}$

Kickbacks from pharmaceutical companies can provide further economic incentives for physicians to prescribe medication, with physicians receiving payments of up to $20 \%$ of the value of the prescription in some cases (Yip and Hsiao, 2008). ${ }^{3}$ These incentives mean that doctors not only have an incentive to prescribe, they have an incentive to prescribe more expensive drugs, which are often the newer and more powerful antibiotics that should be reserved for more dangerous infections.

\section{Physician Induced Demand and Alternative Supply-Side Hypotheses}

In models of physician induced demand (PID), physicians trade off the income gained by inducing patients to consume unnecessary services against the cost of engaging in inducement. The possible costs include a reduction in the doctor's utility from harming patients, or negative effects on the physician's reputation (and his/her ability to induce demand in future). One reason the model is difficult to test

\footnotetext{
${ }^{2}$ There has been some attempt to separate prescribing and dispensing in "grassroots" providers such as community centers after 2009, but this has not affected hospitals.

${ }^{3}$ One source states, "For the pharmaceutical 'Aztreonam', from an unknown manufacturer and priced at 32.3 RMB per box, doctors' commissions are 20\%, or approximately $6.5 \mathrm{RMB}$ per box. The First Hospital of Ningbo City sold 4,079 boxes, for sales of 131,751.7 RMB. 3,255 boxes were for inpatient use, and 824 boxes for outpatient use. 3,600 of those boxes were sold with kickbacks, for an approximate 23,755 RMB paid out". (http://news.ifeng.com/society/1/detail_2010_05/27/1557378_0.shtml)
} 
is that it involves physician motivations. That is, it is not sufficient to observe that the doctor is over-prescribing. One must also show that they know that this is contrary to the patient's best interests.

McGuire (2000) offers an overview of attempts to test the PID model. Many follow Fuchs (1978) and examine the effect of physician density on the consumption of procedures, or they examine the effect of physician fee changes on the volume of services rendered (e.g. Rice, 1983; McGuire and Pauly, 1991; Yip, 1998). Gruber and Owings (1996) take a somewhat different tack and examine the effect of patient availability on the use of Cesarean section for delivery. Another strand of the literature examines "small area variations" in the utilization of medical procedures. Skinner (2011) provides an excellent review. Geographical variations in the use of procedures are often unrelated to average patient health outcomes and these variations have been widely interpreted as evidence of excessive provision of medical care (e.g. Fuchs, 2004). Iizuka (2007) provides a recent test of the PID model. He examines the prescription drug market in Japan and finds that doctors' prescribing patterns are influenced by the size of the markup that they are allowed to charge on drugs.

While the findings in empirical studies of PID are consistent with the PID hypothesis, they are also generally consistent with other models. For instance, Chandra and Staiger (2007) offer a model of small area variations in which doctors in high utilization areas are more skilled in the use of intensive procedures but less skilled in the use of other procedures. Even given proof that doctors overprescribe, or that they respond to economic incentives, it is difficult to observe their motives or 
to prove that they are trading off patient benefits against profits as the PID proposes. Doctors may simply be incompetent, or may have mistaken beliefs about what patients want. Our "gift," "display of knowledge" and "removal of financial incentive" treatments are designed to directly evaluate these possibilities.

\section{Gift Giving in Medical Care}

There is a large literature on gift giving in medical care. Most of this literature focuses on gifts from pharmaceutical companies to doctors. These gifts run the gambit from trips and sponsored dinners to notepads and pens with company logos. It is estimated that pharmaceutical companies spend $\$ 19$ billion per year marketing to 650,000 prescribing doctors in the U.S. (Brennan et al., 2006).

Several studies have established that large gifts can have an influence on prescribing patterns. For example, Orlowski and Wateska (1992) compare the usage of two drugs before and after an all-expense-paid trip and symposium sponsored by one drug maker and found a significant increase in prescriptions of that company's drug. Similarly, Dieperink and Drogemuller (2001) find a three-fold increase in the use of a particular drug after the drug's maker sponsored grand rounds (even though when asked, physicians could not recall who had sponsored the grand rounds).

Controversy still rages about whether a small gift, such as a pen, influences prescribing behavior. For example, Steinman et al. (2001) and Halperin et al. (2004) argue that such small gifts are inconsequential. In contrast, Wazana (2000) argues that even a small gift may have an influence on behavior, while Dana and Loewenstein (2003, pg. 252) state that "by subtly affecting the way the receiver 
evaluates claims made by the gift giver, small gifts may be surprisingly influential."

The economics literature suggests that gifts can be viewed as a signal of the giver's intentions with regard to the relationship (Camerer, 1988) and as such, they call for reciprocity (Carmichael and MacLeod, 1997). These considerations suggest that a small gift from the patient to the physician at the start of the visit could lead to more cooperative behavior on the part of the physician.

If the patient was viewed as demanding antibiotics, then a more cooperative physician would be more likely to prescribe them. If on the other hand, the physician knows that the antibiotics are not appropriate and that they represent a financial burden to the patient, and if the physician does not believe the patient is demanding them, then a cooperative physician will be less likely to prescribe them when he/she receives a gift.

\section{Audit studies of Medical Care}

Audit studies are used in many settings but are relatively uncommon in health care. ${ }^{4}$ They can be used to isolate mechanisms through the use of matched pairs of testers and random assignment. In-person audits can provide not only quantitative data on the outcomes of the audit, but also qualitative information on the process of the audit (Pager 2007). We collect quantitative data about whether or not an

\footnotetext{
${ }^{4}$ There is a literature on "medical audit studies" but this usually refers to an analysis of a sample of patient records. There are few audit studies with simulated patients. Tamblyn et al. (1997) study Canadian physicians treating gastrointestinal problems and found that unnecessary prescriptions were made in about $40 \%$ of cases. Schulman et al. (1999) use an audit with actors to examine differences in the care received by race and gender. Feldman et al. (2006) conduct an interesting audit asking whether a patient's request for medication prevented physicians from properly diagnosing depression.
} 
antibiotic is prescribed, the type of antibiotic, and the price, as well as qualitative information about the patient's experience of the visit. This additional information is helpful in assessing the doctor's motivations.

Currie, Lin, and Zhang (2011) conducted two previous pilot audit studies in 2008 and 2009 which demonstrated the feasibility of the current research. In the first, they found that $65 \%$ of simulated patients with mild cold/flu symptoms in two large Chinese urban areas and $55 \%$ of simulated patients in a rural area received prescriptions for antibiotics. Thus, the study confirmed that there is a high rate of antibiotic abuse in China. In the second, matched pairs of patients in one of the cities went to the same hospital doctor presenting with mild cold/flu symptoms. The patients followed the same script except that one patient said to the doctor "I learned from the internet that simple flu/cold patients should not take antibiotics." This intervention reduced antibiotic prescription rates, but did not prove that the overuse of antibiotics was due to PID. For instance, a non-PID explanation is that doctors assume that patients want antibiotics unless the patients tell them otherwise.

Lu (2011) has recently conducted a small similar study by posing as the "family member" of an imaginary elderly patient with diabetes or hypertension in Beijing. She finds that doctors prescribe more expensive drugs for insured patients than for uninsured patients when the doctors are told that the drugs will be purchased in the doctor's own hospital. ${ }^{5}$

\footnotetext{
${ }^{5}$ There are some potential issues with the Lu study. Only two testers were used (one was the author, and in some cases they visited the same doctor within a week. If these visits are excluded then the results are no longer statistically significant. Also, in several cases doctors refused to prescribe without seeing the patient, and in others, doctors presented multiple treatment options at different price points and the author selected the first plan presented to be considered in the analysis. In the current
} 
None of these studies can disentangle the primary reason for antibiotic abuse in China because they do not combine demand and supply side explanations in one study. The current study represents the first attempt to do so as well as the first experimental audit study of gift giving to physicians.

The leading concern about audit studies is that the auditors may not be effectively matched (Heckman and Siegelman, 1993). In our study, effective matching means that the groups of simulated patients are identical from the point of view of the physicians except for specific departures from the baseline script. We provided extensive training (described further in the Appendix) to ensure that simulated patients behaved in a similar manner and gave the same chief symptoms. We also randomly assigned the patients roles so that it is possible to control for hospital and simulated patient fixed effects in all our estimations.

Another concern in an audit study is that the testers' awareness of the experiment may affect their expectations and/or behaviors and thus influence the results. For example, in a study on racial discrimination in hiring, a black experimenter may be more nervous or less confident than a white experimenter due to the expectation of racial discrimination and their demeanor could affect the study's results.

Our simulated patients were informed about the design and purpose of the study. We felt that since some of them would have been able to infer information about the study from their roles, that it was better to give them all the same information. We tried to minimize the potential impact of this knowledge through training. As

study hospitals were informed that the patients had no insurance at the time the appointment was made. 
discussed further below, simulated patients were trained to dress properly, to strictly follow the standard protocol, and to behave in an even-mannered way during the outpatient visit so that, to the physicians, they differed only in the way indicated by the experimental treatment. In all but the gift treatment, the intervention occurs after the initial examination so that it is also possible to check that there is no difference (relative to the baseline) in the way the physician treats the patient prior to the intervention.

\section{STUDY DESIGN}

Our study was conducted in Beijing's secondary and tertiary hospitals from October 2011 to January 2012, during flu season. We restricted our sample to large general public hospitals as they are more likely to have more than two physicians in the respiratory department, and our auditors were less likely to be conspicuous in a hospital with a large volume of patients. We randomly choose 40 large tertiary hospitals out of the 48 tertiary hospitals in Beijing and 20 hospitals from the 26 secondary hospitals.

We trained 15 auditors (as described below and in the Appendix) who were divided into three groups. Each group was assigned 20 hospitals and each auditor in each group visited each of the 20 hospitals for a total of 300 visits. Within each hospital, each group saw two different doctors so that 120 doctors were seen in all.

We designed a standard protocol which appears in Figure 1. In the protocol, the chief complaint for all simulated patients is, "For the last two days, I've been feeling 
fatigued. I have been having a low-grade fever, slight dizziness, a sore throat, and a poor appetite. This morning, the symptoms worsened so I took my body temperature. It was $37^{\circ} \mathrm{C} . " \quad$ In the baseline, the physician examines the patient and then gives a prescription. After leaving, the patient completes the evaluation form. The evaluation questions covered information about the physician and the complete check-up process, including inquiries the physician made, the physical examination, the diagnosis, and the type and price of the drugs prescribed (if applicable).

We purposely chose very minor symptoms so that it would be difficult for physicians to determine if the infections were viral or bacterial without further tests. Since antibiotics are only effective in treating bacterial infections, it is important for a physician to know the kind of infection a patient acquires before prescribing antibiotics. According to official guidelines (Ministry of Health of the People's Republic of China, 2004), antibiotics should only be prescribed when bacterial infections are confirmed by a patient's symptoms and the results of blood or urine tests. Hence, doctors faced with these vague symptoms should not have prescribed antibiotics and any antibiotic prescription represents antibiotic abuse. Any prescription of powerful second line antibiotics for these mild symptoms is even more concerning.

Simulated patients underwent nine hours of group instruction and individual practice, during which they received instructions on the transcript and how to behave, dress, etc. Students were instructed to take about 15 seconds to give the chief complaint, to ensure that they did not speak too fast or too slow. The main goal was to 
standardize the simulated patients' performance and appearance. To ensure that simulated patients were well trained, after the group instruction and individual practice, simulated patients tested the protocol twice in primary hospitals before the actual implementation of the first audit study.

Table 1 provides a brief taxonomy of our treatments. In the gift treatment (A), a pen worth $1.4 \mathrm{RMB}$ is offered at the beginning of the visit. If the doctor refuses, the patient is instructed to make a second attempt saying "This is just a tiny thing to express my gratitude to you." If the physician still does not accept, then the patient is instructed to say "That's all right," and take the pen back. The rest of the visit is the same as the baseline.

As discussed above, theories of gift giving suggest that receiving a gift inspires a desire to reciprocate (Carmichael and MacLeod, 1997). ${ }^{6}$ If a doctor believed a patient wanted antibiotics prescribed, then a gift should increase the probability that antibiotics are prescribed, if it has any effect. Conversely, if the doctor knows the antibiotic is inappropriate, and does not believe the patient wants it, then he or she should be less likely to prescribe antibiotics when offered a gift. We can also examine other aspects of the visit, such as how long it takes, whether the physician uses more care, or is more courteous, to draw inferences about whether the doctor is reciprocating for the gift.

In Treatment B, following the physical examination, the patient says "I learned

\footnotetext{
${ }^{6}$ Doctors should be more likely to reciprocate if the exchange is viewed as the beginning of an ongoing relationship. Since patients can phone clinics and request appointments with specific doctors, it is not unreasonable to suppose that a doctor might view the visitor as a possible regular patient.
} 
from the internet that simple flu/cold patients should not take antibiotics. Is this true? Can I not take antibiotics unless they are necessary?" Thus, the patient signals to the physician that they have some knowledge of inappropriate antibiotic use while the baseline patient does not.

In Treatment $\mathrm{C}$, following the physical examination, the patient says "Doctor, my sister-in-law works at a drug store. She can offer me a discount if I buy drugs in her store. But I don't know what medicine to take, so could you please write a prescription for me?"

In Treatment $\mathrm{D}$, the patient makes both statements to the physician, indicating that he or she is aware of appropriate antibiotic use, and will not purchase antibiotics from the hospital in any case.

Drug expenditures were normally either listed on the prescription, or easily obtained by going to the pricing window in the hospital pharmacy ( $85 \%$ of our visits). In $2 \%$ of the cases, students obtained the drug price simply by looking at the physician's computer screen while the physician filled out the prescription. In the remaining $13 \%$ of all cases, we found the prices either on the website of the local Price Bureau, or through online search engines.

To analyze the effects of patient knowledge on service quality, we had simulated patients complete an evaluation form in addition to the on-site summary form. After completing all the audits, simulated patients evaluated the service they received from each physician. They rated on a 1 to 10 scale (low to high) the service and their degree of satisfaction. The last question on the evaluation form asked simulated 
patients how willing they were to recommend the physician to their own parents in the event that their parents had similar symptoms. A one indicated that they were against recommending the physician while a 10 indicated that they would definitely recommend the physician.

In order to match patients to doctors, we created a table with the following information for each simulated patient: Visit Order, Visit Date, Role Assigned, Hospital ID and Physician ID. In each visit, the patient's role and his or her visit order was randomly assigned. Appointments were made before the visit, in conformity with the patient's visit order. All patients except the one in role D (display of knowledge and the indication that the patient will purchase the drugs elsewhere) see the same doctor. Patient D visits another physician in the same hospital. Appointments were made with doctors in the respiratory medicine group at the hospitals. This process is illustrated in Table 2, which shows the information for fifteen visits.

Table 3 provides a check on the randomization. It shows that there were no significant differences in the characteristics of the doctor (age and gender), in the number of physicians in the office, in the number of patients in the office, or in the number of patients waiting outside of the physician's office.

Overall, $60 \%$ of physicians accepted the small gift when it was offered. Table 4 shows that whether or not the physician accepted was not significantly related to doctor characteristics or to characteristics of their offices. However, some patients were significantly more likely to have their gifts accepted, so that adding patient fixed 
effects increases the R-squared in these regressions. This result provides an additional motivation for controlling for patient fixed effects in our regression models. When considering the gift treatment, we consider the physician to have been treated if they were offered a gift, whether or not they accepted it. ${ }^{7}$ Hence, we estimate “intent-to-treat" effects.

\section{EMPIRICAL MODELS}

Our experimental audit data can be analyzed by comparing means across the baseline and treatment groups. However, as discussed above, one of the main concerns about an audit study is that doctors might react differently to different auditors. Therefore, we also estimate models controlling for observable characteristics of auditors and of doctors, as well as for the order in which patients were seen. We first estimate models of the following form:

$$
\text { (1) } Y_{i j k}=\alpha_{0}+\alpha_{1} \text { Role }_{i j k}+\alpha_{2} X_{i}+\alpha_{3} Z_{j}+\alpha_{4} \operatorname{Order}_{i j k}+\varepsilon_{i j k}
$$

where $\mathrm{i}$ indicates the simulated patient, $\mathrm{j}$ indicates the physician, $\mathrm{k}$ indicates the hospital, $\mathrm{Y}_{\mathrm{ijk}}$ is the outcome of interest for simulated patient i's visit with physician $\mathrm{j}$ in hospital $\mathrm{k}$; Role $\mathrm{ijk}_{\mathrm{j}}$ is a vector of dummy variables indicating the treatment (if different from the baseline), $\mathrm{X}_{\mathrm{i}}$ is a vector of patient characteristics (patient's gender; all students were 21 ); $\mathrm{Z}_{\mathrm{j}}$ is a vector of physician $\mathrm{j}$ 's characteristics (gender and a categorical variable for the physician's age, 20-30, 31-40, 41-50 and 51+ years); ${ }^{8}$ and $\operatorname{Order}_{\mathrm{ijk}}$ is a vector of dummy variables indicating whether the patient was the

\footnotetext{
${ }^{7}$ One might also view the patient's statement about his or her esteem for doctors as part of the gift. ${ }^{8}$ This age variable is based on the patient's assessment of the physician's age.
} 
second, third, or fourth patient seen by the doctor.

We next estimate models including hospital fixed effects since there might be systematic differences between hospitals. Our most restrictive models include patient fixed effects as well and take the following form:

(2) $\mathrm{Y}_{\mathrm{ijk}}=\beta_{0}+\beta_{1}$ Role $_{\mathrm{ijk}}+\beta_{2} \mathrm{Z}_{\mathrm{j}}+\beta_{3} \operatorname{Order}_{\mathrm{ijk}}+\delta_{\mathrm{k}}+\eta_{\mathrm{i}}+\varepsilon_{\mathrm{ijk}}$, where most variables are defined as above, $\delta_{\mathrm{k}}$ is a vector of hospital fixed effects, and $\eta_{\mathrm{i}}$ is a vector of patient fixed effects.

The parameters of interest in these models are the vector $\beta_{1}$, which show the effect of the four treatments relative to the baseline. When $\mathrm{Y}_{\mathrm{ijk}}$ is a health care utilization measure, such as the prescription rate for antibiotics, we expect $\beta_{1}$ to be significantly negative if the treatments decrease utilization. When $\mathrm{Y}_{\mathrm{ijk}}$ is a measure of good service quality, such as whether the physician describes possible side effects, we expect $\beta_{1}$ to be significantly negative if the treatments degrade service quality and significantly positive if the treatments improves service quality.

\section{RESULTS}

Table 5 shows the mean outcomes for the baseline and the four treatments. The first row shows that the patient almost always receives a prescription for some type of medication. There are many Chinese medicines that the doctor could prescribe. However, the second row indicates that there is an alarmingly high rate of antibiotics prescription: In the baseline, $63.3 \%$ of these simple cold/flu patients receive a prescription for antibiotics which is consistent with Currie, Lin, and Zhang (2011). 
Columns 2 through 5 of Table 5 indicate that there is a great deal of variation in antibiotics prescription rates across our experimental treatments.

Column 2 shows results for the gift-giving treatment (A). Remarkably, while $100 \%$ of physicians in this treatment made a prescription, only $50 \%$ of the physicians who were offered a gift prescribed antibiotics. This is lower than the baseline rate of $63 \%$. The difference in raw means is not statistically significant, gift giving results in significantly lower rates of antibiotic prescription in models with patient fixed effects. Column 3 focuses on Treatment B, the display of knowledge about antibiotics. Only $43.3 \%$ of these patients received prescriptions for antibiotics, a statistically significant reduction of 20 percentage points from the baseline.

Column 4 shows the results of Treatment $\mathrm{C}$ in which patients indicated that they would purchase drugs elsewhere. Only $11.7 \%$ of these patients received prescriptions for antibiotics, which represents a statistically and behaviorally significant a reduction of 51.6 percentage points from the baseline. Similarly, column 5 shows estimates from Treatment D in which patients both displayed knowledge about antibiotics and indicated that they would purchase elsewhere. These patients had the lowest antibiotics prescription rate of any group at only $8.3 \%$.

The rest of Table 5 provides more detail about types of drugs prescribed, drug expenditures, and service quality. Panel B shows results for the types of drugs prescribed, conditional on prescription. The gift giving treatment has no significant effect. Treatment B (the display of knowledge) reduces the prescription of Grade 2 antibiotics from $15.3 \%$ in the baseline to $3.4 \%$. This result suggests that physicians 
know that it is inappropriate to prescribe powerful Grade 2 antibiotics for simple cold/flu symptoms, and that they are much less likely to do so if the patient might know that this is particularly inappropriate.

The "no purchase" treatments C and D have the largest effects, significantly reducing the number of drugs prescribed, the probability that two or more drugs are prescribed, and prescriptions for Grade 1 antibiotics. Prescription rates for Grade 2 antibiotics fall to zero in this treatment, suggesting that the only motive for prescribing these drugs for simple cold/flu symptoms is financial.

Panel $\mathrm{C}$ of Table 5 shows that all of our treatments reduce drug expenditures significantly relative to the baseline. The "gift" treatment reduces them by a modest 21.8 RMB, while the "no purchase" treatment reduces them by much larger 66.4 RMB. The "display" treatment is in between, reducing drug expenditures by 33.6RMB.

Turning to service quality, Panel D shows that there were no significant differences in the actual examination given to the patients after gift giving and prior to any of the other treatment interventions. However, Panel E shows that there were differences in patient-doctor interactions. In the gift treatment, physicians were significantly more likely to give helpful advice such as suggesting that the patient drink more water or get more rest ${ }^{9}$, and auditors indicated that they would be significantly more likely to recommend the physician to their own parents, suggesting that the overall interaction was more satisfactory. In contrast, in the "display of

${ }^{9}$ Physicians also sometimes counseled patients to wear warm cloths, eat more fruit, or avoid strenuous activity. We also coded this variable 1 if the physician offered this advice. 
knowledge" treatment, physicians were significantly less likely to respond politely at the end of the visit. In the two "no purchase" treatments, physicians were also significantly less likely to give helpful advice and patients were less likely to say that they would recommend the doctor to their own parents.

Finally, Panel F examines several aspects of service quality conditional on drug prescription. In the baseline, only $32.2 \%$ of physicians offer instructions about drug usage, and only $5.1 \%$ inform patients about side effects without being asked. Both of these proportions fall to zero in the two "no purchase" treatments, a difference that is statistically significant.

Table 6 shows our results regarding prescription in a regression context. As discussed above, it is important to control for possible differences in doctor's reactions to our auditors as well as for any systematic differences across hospitals. The first four columns focus on whether antibiotics are prescribed, and show that adding control variables, hospital fixed effects, or patient fixed effects has little impact on the point estimates. There is some evidence that male patients are more likely to be prescribed antibiotics, though this coefficient is no longer statistically significant in models with hospital fixed effects.

The main results regarding antibiotics prescription are in line with those in Table 5 and indicate that the "no purchase" treatment has by far the largest impact on prescription rates, though gift giving and a display of knowledge also reduce antibiotic prescriptions significantly once patient fixed effects are included in the 
model. $^{10}$ The interaction between "display" and "no purchase" is not statistically significant, but the coefficient estimate suggests that consistent with Table 5, a display of knowledge has little additional effect on antibiotics prescriptions when the financial incentive to prescribe has been eliminated.

Columns 5 to 7 focus on additional aspects of antibiotics prescription in models that include all of the control variables, hospital fixed effects, and patient fixed effects. Column 5 indicates that doctors in the "display" and "no purchase" treatments are less likely to prescribe two or more drugs, while column 6 indicates that grade 2 antibiotics are significantly less likely to be prescribed. Finally, column 7 shows that drug expenditures are reduced by all of our treatments, with the largest reductions associated with the "no purchase" treatments.

Table 7 explores the effects of the treatment on service quality. We do not show the control variables in this table, since they were never statistically significant. The estimates in the top row of both panels indicate that gift giving resulted in significantly better service. Doctors were more likely to use a stethoscope, more likely to offer helpful advice such as suggesting that the patient drink more water, and more likely to inform the patient about drug side effects. Patients perceived better quality service and were 1.5 points (out of 10 ) more likely to say that they would recommend the doctor to their own parents.

The display of knowledge treatment had relatively little effect on service quality, though physicians were less likely to respond politely after being thanked at the end

\footnotetext{
10 The coefficient on the gift treatment becomes significant once patient fixed effects are added which is perhaps consistent with the fact that some patients were more successful than others in having their gifts accepted.
} 
of the visit, and patients indicated that they would be half a point less likely to recommend the doctor to their own parents. ${ }^{11}$

The "no purchase" treatment had larger negative effects on service quality. Physicians were less likely to instruct the patient on drug usage, less likely to offer helpful advice such as drinking more water, and less likely to respond politely after being thanked. Patients were, in turn, 1.1 points less likely to say that they would recommend the physicians to their own parents. Visits were also shorter in this treatment, though that difference is significant only at the $90 \%$ level of confidence.

\section{DISCUSSION AND CONCLUSIONS}

We use the audit study method to examine supply and demand factors related to the overuse of antibiotics in China, and the hypothesis that overuse is caused by physician-induced demand. Our results provide evidence that antibiotics overuse is related to physician financial incentives. Eliminating these incentives dramatically reduces inappropriate prescription of antibiotics for cold/flu symptoms, and completely eliminates the prescription of expensive and powerful Grade 2 antibiotics for these patients.

Our study is the first to address all of the leading explanations for the overuse of antibiotics in a single framework. Our estimates suggest that at least in Beijing hospitals, physicians do not prescribe antibiotics primarily because patients demand them, because doctors believe that patients want antibiotics, or because physicians

${ }^{11}$ As shown in the Appendix, simulated patients were also asked a number of other questions about service quality, such as whether they felt that the doctor treated them courteously and respect. We did not find significant effects of the treatments on these other questions, with the exception that patients in the "no-incentive" treatment $\mathrm{C}$ reported that doctors were less likely to treat them with consideration. 
erroneously believe that such prescriptions are in the best interests of the patient. Indeed, physicians who are offered a small gift improve service quality and reduce prescriptions of antibiotics. Hence, doctors who are making a greater effort to please patients reduce rather than increase antibiotic prescriptions.

These results can be contrasted with the treatment in which patients display knowledge about the appropriate use of antibiotics. This treatment also resulted in reduced prescription rates, but degraded service quality. The fact that we measure the effects of our treatments on service quality as well as on antibiotic prescriptions helps us to understand the potential costs and benefits of different interventions from the point of view of the patient. Only gift giving resulted in both lower rates of unnecessary antibiotic prescription and improved patient service.

The gift-giving treatment also provides the first experimental evidence that doctors can be influenced by token gifts, such as pens. Hence, this evidence may be of interest in the wider debate about the role of gifts in medicine, and supports Dana and Loewenstein's (2003) contention that even small gifts can be influential.

Our results are suggestive about the types of reforms that could lead to lower use of antibiotics in China, and perhaps in other places where overuse is a significant problem (e.g. India, see Das and Hammer, 2007). They suggest that payment reforms would likely have the largest impact on this problem, but that it might also be possible to achieve some reduction in inappropriate antibiotic use by, for example, a widespread public advertising campaign noting that antibiotics are not appropriate for the treatment of simple colds and the flu, or by requiring hospitals to post notices with 
this information in examination rooms. An important caveat is that any specific reform to hospital payments systems in China could have unintended effects, and would have to be specifically evaluated. 


\section{REFERENCES}

Bennett, Daniel,Che-Lun Huang and Tsai-Ling Lauderdale, "Health Care Competition and Antibiotic Use in Taiwan," Harris School of Policy Studies, 8(2010)

Bi, Peng,Shilu Tong and Kevin A. Parton, "Family Self-medication and Antibiotics Abuse for Children and Juveniles in a Chinese City," Social Science and Medicine 50 (2000), 1445-1450.

Brennan, TroyenA., David J. Rothman, Linda Blank, David Blumenthal, Susan C. Chimonas, Jordan J. Cohen, Janlori Goldman, Jerome P. Kassirer, Harry Kimball, James Naughton and Neil Smelser, "Health Industry Practices that Create Conflicts of Interest," JAMA: the Journal of the American Medical Association 295 (2006), 429-433.

Camerer, Colin, "Gifts as Economic Signals and Social Symbols," American Sociological Review 94(1988), 180-214.

Carmichael, H. Lorne and W. Bentley MacLeod, "Gift Giving and the Evolution of Cooperation," International Economic Review 38 (1997), 485-509.

Cars,Håkan and Anders Håkansson, "To Prescribe-or not to Prescribe-antibiotics: District Physicians' Habits Vary Greatly, and are Difficult to Change," Scandinavian Journal of Primary Health Care 13 (1995), 3-7.

Chandra, Amitabh and Douglas Staiger, "Productivity Spillovers in Healthcare: Evidence from the Treatment of Heart Attacks," Journal of Political Economics 115(2007), 103-140.

Chen,Meiping, "Analysis on the Condition of, Reasons for and Control on Antibiotic Abuse," Jiangsu Health Care Management 16 (2005), 49-50. (in Chinese)

Currie, Janet,Wanchuan Lin and Wei Zhang, "Patient Knowledge and Antibiotic Abuse: Evidence from an Audit Study in China," Journal of Health Economics 30(2011),933-949.

Dana, Jason and George Loewenstein, "A Social Science Perspective on Gifts to Physicians from Industry," JAMA: the Journal of the American Medical Association290(2003), 252-255.

Dar-Odeh, NajlaSaeed, Osama Abdalla Abu-Hammad, Mahmoud Khaled Al-Omiri, AmeenSamehKhraisat and Asem Ata Shehabi, "Antibiotic Prescribing Practices by Dentists: A Review," Therapeutics and Clinic Risk 
Management 6(2010), 301-306.

Das, Jishnu and Jeffrey Hammer, "Location, Location, Location: Residence, Wealth, and the Quality of Medical Care in Delhi, India," Journal of Telemedicine and Telecare 17(2011), 336-337.

Dieperink, Michael E., Drogemuller and Lisa Drogemuller, "Industry-Sponsored Grand Rounds and Prescribing Behavior," JAMA: the Journal of the American Medical Association, 285(2001), 1443-1444.

Dong, Hengjin,LennartBogg, Keli Wang, ClasRehnberg and VinodDiwan, “A Description of Outpatient Drug Use in Rural China: Evidence of Differences Due to Insurance Coverage," The International Journal of Health Planning and Management 14 (1999), 41-56.

Dranove, David, "Pricing by Non-profit Institutions: the Case of Hospital Cost-shifting," Journal of Health Economics 7 (1988), 47-57.

Egglestion, Karen and Winnie Yip, "Hospital Competition Under Regulated Prices: Application to Urban Health Sector Reforms in China," Tufts University Working Paper (2004).

Eggleston, Karen, Ling Li, QingyueMeng, Magnus Lindelow and Adam Wagstaff, "Health Service Delivery in China: A Literature Review," Health Economics 17 (2008a), 149-65.

Eggleston, Karen, Yu-Chu Shen, Joseph Lau, Christopher H. SchmidandJia Chan, "Hospital Ownership and Quality of Care: What Explains the Different Results in the Literature?" Health Economics 17 (2008b.): 1345-1362.

Feldman, Mitchell D., Peter Franks, Ronald M. Epstein, Carol E. Franz, and Richard L. Kravitz, "Do Patient Requests for Antidepressants Enhance or Hinder Physicians' Evaluation of Depression? A Randomized Controlled Trial," Medical Care 44 (2006), 1107-1113.

Fuchs, Victor R, "Reflections on the Socio-economic Correlates of Health," Journal of Health Economics 23 (2004): 653-661.

Fuchs, Victor R, "The Supply of Surgeons and the Demand for Operations," The Journal of Human Resources 13(1978), 35-56.

Gong, Aiqun, "The Reasons for and Consequences of Antibiotic Abuse," Heilongjiang Medicine Journal 22 (2009), 368-369. (in Chinese)

Gruber, Jonathan and Maria Owings, "Physician Financial Incentives and Cesarean 
Section Delivery,"RAND Journal of Economics 27 (1996), 99-123.

Guo, Dongmei, "Analysis of Current Situation of the Anti-infective Market in China," China Pharmacy15 (2004): 528-531. (in Chinese)

Halperin, Edward C., Paul Hutchison and Robert C. Barrier, “A Population-Based Study of the Prevalence and Influence of Gifts to Radiation Oncologists from Pharmaceutical Companies and Medical Equipment Manufacturers," Journal of Radiation Oncology 59 (2004), 1477-1483.

Heaton, Paul and Eric Helland, "Does Treatment Respond to Reimbursement Rates? Evidence from Trauma Care," RAND Working Paper No.WR-648-ICJ, Published by the RAND Corporation, Santa Monica (2009).

Hew, Chee, "Healthcare in China: Towards Greater Access, Efficiency and Quality," New York IBM Business Consulting Service working paper (2006).

Hsiao, William C.L. and Yuanli Liu, "Economic Reform and Health— Lessons from China," The New England Journal of Medicine 335(1996), 430-432.

Hu, Suping,Xiuheng Liu and Yan Peng, "Assessment of Antibiotic Prescription in Hospitalized Patients at a Chinese University Hospital," Journal of Infection 46 (2003),161-163.(in Chinese)

Iizuka, Toshiaki, 'Experts' Agency Problems: Evidence from the Prescription Drug Market in Japan," RAND Journal of Economics 38 (2007), 844-862.

James, William D., Timothy G. Berger,and Dirk M. Elston, "Contact dermatitis and drug eruptions" (pp. 88-137),in James, William D., Timothy G. Berger,and Dirk M. Elston (Eds.), Andrews' diseases of the skin (China: Elsevier, 2011).

Liu, Xingzhu,Yuanli Liu and Ningshan Chen, "The Chinese Experience of Hospital Price Regulation,"Health Policy and Planning 15 (2000), 157-163.

Lu, Fangwen,“ Insurance Coverage and Agency Problems in Doctor Prescriptions: Evidence from a Field Experiment in China,"Working Paper,2011.

McGuire, Thomas G., "Physician Agency," Handbook of Health Economics 1(2000), 461-536.

McGuire, Thomas G. and Mark V. Pauly, "Physician Response to Fee Changes with Multiple Payers."Journal of Health Economics 10 (1991), 385-410.

Ministry of Health of the People's Republic of China, "Hospital Infection Control 
Practices," (2000),

http://www.moh.gov.cn/publicfiles/business/htmlfiles/mohyzs/s3593/200804/186 26.htm. (in Chinese).

Ministry of Health of the People's Republic of China, China Health Statistics Yearbook 2009 (Beijing: Peking Union Medical College Publishing House,2009 )(in Chinese),

Ministry of Health of the People's Republic of China, State Administration of Traditional Chinese Medicine of the People's Republic of China, Health Department of General Logistics, "Guiding Principles for Clinical Application of Antibacterial, " Chinese Medicine Modern Distance Education of China 2 (2006), 10-11 (in Chinese).

Orlowski, James P. and Leon Wateska, "The Effects of Pharmaceutical Firm Enticements on Physician Prescribing Patterns: There's No Such Thing as a Free Lunch," Chest, 102(1992), 270-273.

Pager, Devah, "The Use of Field Experiments for Studies of Employment Discrimination: Contributions, Critiques, and Directions for the Future,"The Annals of the American Academy of Political and Social Science 609 (2007), 104-133.

Phelps, Charles E., “Bug/drug Resistance: Sometimes Less Is More,”Medical Care 27 (1989),194-203.

Rice, Thomas H., "The Impact of Changing Medicare Reimbursement Rates on Physician-induced Demand," Medical Care 21 (1983), 803-815.

Roumie, ChristianneL.,Natasha B. Halasa, Carlos G. Grijalva, Kathryn M. Edwards, Yuwei Zhu, Robert S. Dittus and Marie R. Griffin, "Trends in Antibiotic Prescribing for Adults in the United States-1995 to 2002,"Journal of General Internal Medicine 20 (2005), 697-702.

Schulman, Kevin, Jesse A. Berlin, William Harless, Jon F. Kerner, ShyrlSistrunk,Bernard J. Gersh, Ross Dubé, Christopher K. Taleghani,Jennifer E. Burke,Sankey Williams, John M. Eisenberg, William Ayers and José J. Escarce, "The Effect of Race and Sex on Physicians' Recommendations for Cardiac Catherterization,"New England Journal of Medicine 340(1999), 618-626.

Schwartz, Bryan, Ralph Gonzales, John F. Steiner and Merle A. Sande, "Why do Physicians Prescribe Antibiotics for Children with Upper Respiratory Tract 
Infections?'JAMA: the Journal of the American Medical Association279 (1998), 881-882.

Siegelman, Peter and James Heckman, "Clear and Convincing Evidence: Measurement of Discrimination in America" (Washington D.C., NY: Urban Institute, 1993).

Shehab, Nadine, Priti R. Patel, Arjun Srinivasan and Daniel S. Budnitz, "Emergency Department Visits for Antibiotic-Associated Adverse Events," Clinical Infectious Diseases, 47(2008), 735-743.

Skinner, Jonathan, "Causes and Consequences of Regional Variations in Health Care," (pp. 45-93), Handbook of Health Economics, Vol.2 (Elsevier, 2011).

Steinman, Michael A., Michael G. Shlipak and Stephen J. McPhee," Of Principles and Pens: Attitudes and Practices of Medicine Housestaff toward Pharmaceutical Industry Promotion," American Journal of Medicine 110(2001), 551-557.

Sun, Xiaoyun,Sukhan Jackson, Gordon A. Carmichael and Adrian C. Sleigh, "Prescribing behavior of village doctors under China's New Cooperative Medical Scheme," Social Science and Medicine 68 (2009), 1775-1779.

Tamblyn, Robyn, W. Dale Dauphinee, Rolan Grad, Peter McLeod, Linda Snell, "Unnecessary Prescribing of NSAIDs and the Management of NSAID-Related Gastropathy in Medical Practice," Annals of Internal Medicine 15(1997), 429-438.

Tang, Shenglan, Jing Sun, Gang Qu and Wen Chen "Pharmaceutical Policy in China: Issues and Problems," (2007), http://archives.who.int/tbs/ChinesePharmaceuticalPolicy/English_Background_D ocuments/summarypapers/PPChinaIssuesProblemsShenglan.doc.

Wazana, Ashley, "MDs, Physicians and the Pharmaceutical Industry: Is a Gift Ever Just a Gift?" JAMA: the Journal of the American Medical Association 283 (2000), 373-380.

Yao, Kai-hu and Yong-hong Yang, "Streptococcus Pneumoniae Diseases in Chinese: Past, Present and Future," Vaccine 26 (2008), 4425-4433.

Yip, Winnie C., "Physician Response to Medicare Fee Reductions: Changes in the Volume of Coronary Artery Bypass Graft (CABG) Surgeries in the Medicare and Private Sectors," Journal of Health Economics 17 (1998), 675-699.

Yip, Winnie C. andWilliam C. Hsiao, "The Chinese Health System at a Crossroads," Health Affairs 27 (2008), 460-468. 
Zhang, Ruifang,Eggleston Karen, Rotimi Vincent andZeckhauser Richard, “Antibiotic Resistance as A Global Threat: Evidence from China, Kuwait and the United States," Global Health 2 (2006), 1-14. 
Figure 1: Physician-visiting Protocol

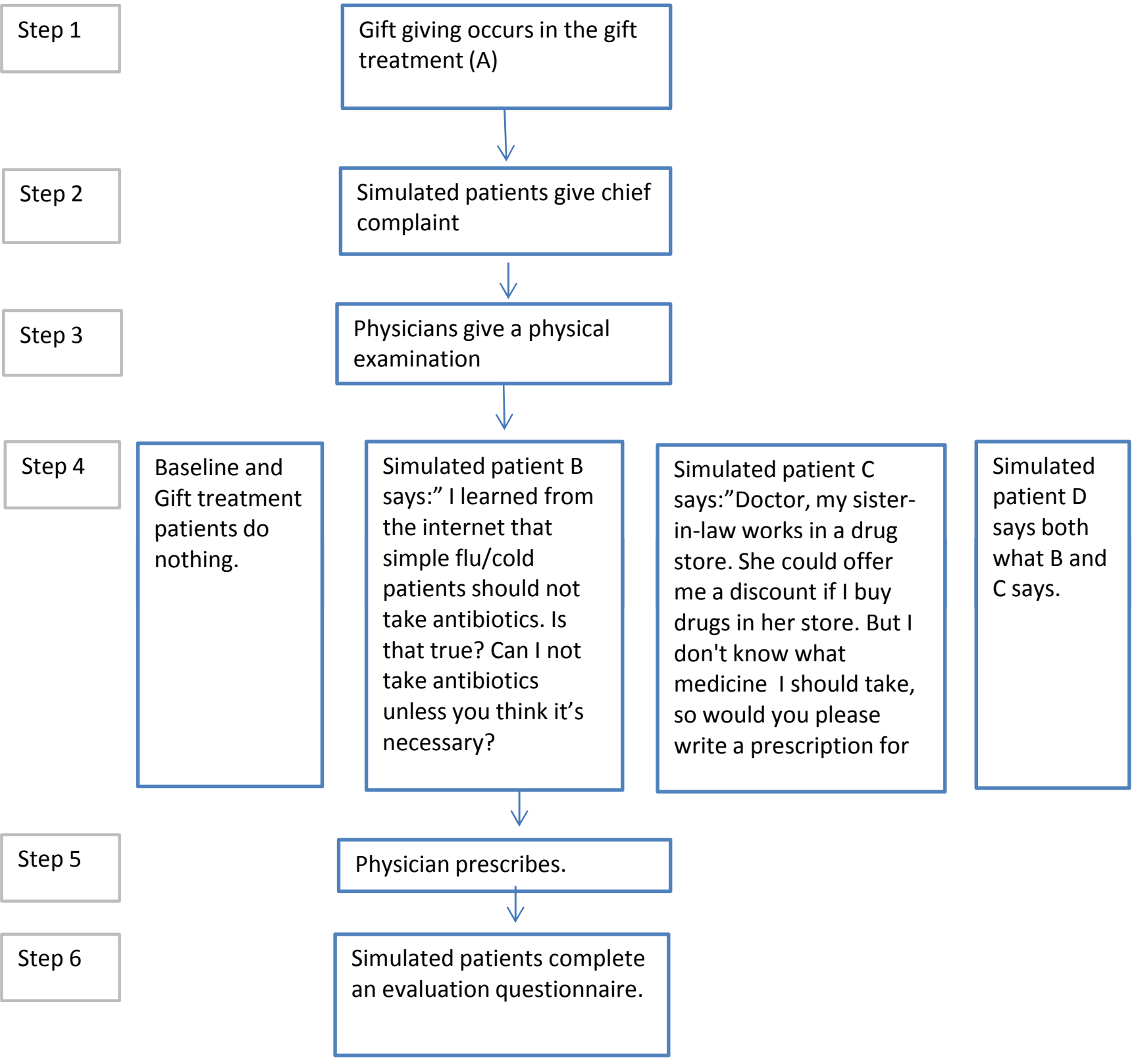


Table 1: Taxonomy of Treatments

\begin{tabular}{lll}
\hline \hline & No-Display & Display \\
\hline Incentive & $\begin{array}{l}\text { Baseline/Type } \\
\text { Agift }\end{array}$ & Type B \\
No-incentive & Type C & Type D \\
\hline \hline
\end{tabular}

Table 2: Determining the role and order of simulated patients (An example showing the first 15 observations)

\begin{tabular}{|c|c|c|c|c|c|c|}
\hline $\begin{array}{l}\text { Case } \\
\text { (1) } \\
\end{array}$ & $\begin{array}{c}\text { Visit Date } \\
\text { (2) }\end{array}$ & $\begin{array}{c}\text { Student } \\
\text { ID } \\
(3) \\
\end{array}$ & $\begin{array}{c}\text { Role } \\
\text { Assigned } \\
(4) \\
\end{array}$ & $\begin{array}{c}\text { Visit } \\
\text { Order } \\
\text { Assigned } \\
\text { (5) }\end{array}$ & $\begin{array}{c}\text { Hospital } \\
\text { ID } \\
(6) \\
\end{array}$ & $\begin{array}{c}\text { Physician } \\
\text { ID } \\
(7) \\
\end{array}$ \\
\hline $1-1$ & Nov. $15^{\text {th }}$ & 1 & Baseline & Fourth & A & A1 \\
\hline $1-2$ & Nov. $14^{\text {th }}$ & 2 & $\mathrm{~A}_{\text {gift }}$ & Third & A & A1 \\
\hline $1-3$ & Nov. $12^{\text {th }}$ & 3 & $\mathrm{C}$ & Second & A & A1 \\
\hline $1-4$ & Nov. $17^{\text {th }}$ & 4 & D & Fifth & A & $\mathrm{A} 2$ \\
\hline $1-5$ & Nov. $11^{\text {th }}$ & 5 & B & First & A & A1 \\
\hline $2-1$ & Dec. $8^{\text {th }}$ & 1 & Baseline & Fourth & B & B1 \\
\hline $2-2$ & Dec. $2^{\text {nd }}$ & 2 & $\mathrm{C}$ & First & B & B1 \\
\hline $2-3$ & Dec. $4^{\text {th }}$ & 3 & $\mathrm{D}$ & Third & B & B2 \\
\hline $2-4$ & Dec. $3^{\text {rd }}$ & 4 & $\mathrm{~A}_{\text {gift }}$ & Second & B & B1 \\
\hline $2-5$ & Dec. $9^{\text {th }}$ & 5 & B & Fifth & B & B1 \\
\hline $3-1$ & Dec. $14^{\text {th }}$ & 1 & B & Third & $\mathrm{C}$ & C1 \\
\hline $3-2$ & Dec. $12^{\text {th }}$ & 2 & $\mathrm{C}$ & Second & $\mathrm{C}$ & C1 \\
\hline $3-3$ & Dec. $9^{\text {th }}$ & 3 & $A_{\text {gift }}$ & First & $\mathrm{C}$ & C1 \\
\hline $3-4$ & Dec. $16^{\text {th }}$ & 4 & Baseline & Fifth & $\mathrm{C}$ & C1 \\
\hline $3-5$ & Dec. $15^{\text {th }}$ & 5 & $\mathrm{D}$ & Fourth & $\mathrm{C}$ & $\mathrm{C} 2$ \\
\hline
\end{tabular}

Notes: In Treatment $\mathrm{D}$, the patient makes both statements to the physician, indicating that he or she is aware of appropriate antibiotic use, and will not purchase antibiotics from the hospital in any case. The order of the two lines is also randomly determined before visiting the physician. 
Table 3: Randomization Check

\begin{tabular}{|c|c|c|c|c|c|c|}
\hline Variable & $\begin{array}{c}\text { Baseline } \\
\text { (1) }\end{array}$ & $\begin{array}{c}\text { A_Gift } \\
(2)\end{array}$ & $\begin{array}{c}\text { B_Display } \\
\text { (3) }\end{array}$ & $\begin{array}{c}\text { C_No } \\
\text { Purchase } \\
\text { (4) }\end{array}$ & $\begin{array}{c}\text { D_Display+ } \\
\text { No } \\
\text { Purchase } \\
\text { (5) }\end{array}$ & $\begin{array}{c}\text { Equal } \\
\text { Means Test } \\
\text { p-value } \\
(6)\end{array}$ \\
\hline Physician's age & $\begin{array}{l}1.68 \\
{[0.099]}\end{array}$ & $\begin{array}{l}1.68 \\
{[0.099]}\end{array}$ & $\begin{array}{l}1.68 \\
{[0.099]}\end{array}$ & $\begin{array}{l}1.68 \\
{[0.099]}\end{array}$ & $\begin{array}{l}1.67 \\
{[0.134]}\end{array}$ & 1.00 \\
\hline Proportion of male physicians & $\begin{array}{l}0.43 \\
{[0.064]}\end{array}$ & $\begin{array}{l}0.43 \\
{[0.064]}\end{array}$ & $\begin{array}{l}0.43 \\
{[0.064]}\end{array}$ & $\begin{array}{l}0.43 \\
{[0.064]}\end{array}$ & $\begin{array}{l}0.38 \\
{[0.063]}\end{array}$ & 0.97 \\
\hline Proportion of office-sharing physicians & $\begin{array}{l}0.28 \\
{[0.064]}\end{array}$ & $\begin{array}{l}0.28 \\
{[0.059]}\end{array}$ & $\begin{array}{l}0.28 \\
{[0.064]}\end{array}$ & $\begin{array}{l}0.28 \\
{[0.064]}\end{array}$ & $\begin{array}{l}0.30 \\
{[0.065]}\end{array}$ & 1.00 \\
\hline $\begin{array}{l}\text { Number of (other) physicians in the office } \\
\text { (conditional on office-sharing) }\end{array}$ & $\begin{array}{l}1.71 \\
{[0.194]}\end{array}$ & $\begin{array}{l}1.59 \\
{[0.193]}\end{array}$ & $\begin{array}{l}1.64 \\
{[0.169]}\end{array}$ & $\begin{array}{l}1.64 \\
{[0.169]}\end{array}$ & $\begin{array}{l}1.73 \\
{[0.182]}\end{array}$ & 0.98 \\
\hline $\begin{array}{l}\text { Number of (other) patients in the office } \\
\text { (unconditional on office-sharing) }\end{array}$ & $\begin{array}{l}0.56 \\
{[0.143]}\end{array}$ & $\begin{array}{l}0.58 \\
{[0.124]}\end{array}$ & $\begin{array}{l}0.48 \\
{[0.132]}\end{array}$ & $\begin{array}{l}0.58 \\
{[0.154]}\end{array}$ & $\begin{array}{l}0.56 \\
{[0.128]}\end{array}$ & 0.98 \\
\hline $\begin{array}{l}\text { Number of (other) patients in the office } \\
\text { (conditional on office-sharing) }\end{array}$ & $\begin{array}{l}2.00 \\
{[0.234]}\end{array}$ & $\begin{array}{l}1.94 \\
{[0.181]}\end{array}$ & $\begin{array}{l}1.71 \\
{[0.266]}\end{array}$ & $\begin{array}{l}2.07 \\
{[0.286]}\end{array}$ & $\begin{array}{l}1.73 \\
{[0.182]}\end{array}$ & 0.76 \\
\hline Number of patients in the waiting areas & $\begin{array}{l}2.72 \\
{[0.348]}\end{array}$ & $\begin{array}{l}2.53 \\
{[0.260]}\end{array}$ & $\begin{array}{l}2.98 \\
{[0.503]}\end{array}$ & $\begin{array}{l}3.00 \\
{[0.400]}\end{array}$ & $\begin{array}{l}3.04 \\
{[0.300]}\end{array}$ & 0.71 \\
\hline $\begin{array}{l}\text { Average Number of patients in the waiting areas } \\
\text { (per doctor) }\end{array}$ & $\begin{array}{l}2.32 \\
{[0.350]}\end{array}$ & $\begin{array}{l}2.07 \\
{[0.227]}\end{array}$ & $\begin{array}{l}2.61 \\
{[0.513]}\end{array}$ & $\begin{array}{l}2.54 \\
{[0.406]}\end{array}$ & $\begin{array}{l}2.44 \\
{[0.288]}\end{array}$ & 0.75 \\
\hline Observations & 60 & 60 & 60 & 60 & 60 & 1 \\
\hline
\end{tabular}

Notes: Standard deviations are in brackets. The reported p-value is from a test statistic generated by Wilks' lambda. 
Table 4: Gift Acceptance Decision

Dependent Variable : Gift Acceptance

\begin{tabular}{|c|c|c|c|}
\hline Independent Variable & $(1)$ & $(2)$ & (3) \\
\hline \multirow[t]{2}{*}{ Doctor's Age: 41-50 } & -0.12 & -0.07 & -0.11 \\
\hline & [0.139] & [0.138] & {$[0.168]$} \\
\hline \multirow[t]{2}{*}{ Doctor's Age: >=51 } & 0.16 & 0.21 & 0.07 \\
\hline & [0.186] & [0.182] & {$[0.220]$} \\
\hline \multirow[t]{2}{*}{ Doctor is Male } & 0.09 & 0.04 & -0.03 \\
\hline & [0.121] & [0.121] & {$[0.134]$} \\
\hline \multirow[t]{2}{*}{ Patient is Male } & 0.18 & 0.17 & \\
\hline & [0.127] & [0.122] & \\
\hline \multirow[t]{2}{*}{ Share an office } & & -0.22 & -0.26 \\
\hline & & [0.343] & [0.389] \\
\hline \multirow[t]{2}{*}{ Share an office * Number of other physician in the office } & & -0.08 & -0.05 \\
\hline & & {$[0.246]$} & [0.325] \\
\hline \multirow[t]{2}{*}{ Share an office * Number of other patients in the office } & & 0.06 & 0.05 \\
\hline & & [0.261] & {$[0.347]$} \\
\hline \multirow[t]{2}{*}{ Other people paying attention to the gift giving } & & -0.28 & -0.1 \\
\hline & & {$[0.201]$} & [0.248] \\
\hline \multirow[t]{2}{*}{ Constant } & $0.67^{*}$ & $0.77^{\star}$ & 0.54 \\
\hline & [0.142] & {$[0.147]$} & {$[0.357]$} \\
\hline Observations & 60 & 60 & 60 \\
\hline R-squared & 0.25 & 0.36 & 0.51 \\
\hline
\end{tabular}

Notes:Standard errors are in brackets. Only Treatment A (gift) simulated patients are included.

The ommited doctor's age dummy is "Doctor's Age: 31-40".

An asterisk indicates that the variable is significant at the $95 \%$ level of confidence. 
Table 5: Mean Outcomes for Baseline and Four Treatments

\begin{tabular}{|c|c|c|c|c|c|}
\hline Dependent variable & Baseline & A_Gift & B_Display & $\begin{array}{c}\text { C_No } \\
\text { Purchase } \\
(4) \\
\end{array}$ & $\begin{array}{c}\text { D_Display+ } \\
\text { No } \\
\text { Purchase } \\
(5) \\
\end{array}$ \\
\hline \multicolumn{6}{|l|}{ Panel A. Prescription Rates } \\
\hline Prescription rate & $\begin{array}{c}0.983 \\
{[0.017]}\end{array}$ & $\begin{array}{c}1 \\
{[0.000]}\end{array}$ & $\begin{array}{c}0.967 \\
{[0.023]}\end{array}$ & $\begin{array}{c}0.933 \\
{[0.032]}\end{array}$ & $\begin{array}{c}0.867^{*} \\
{[0.044]}\end{array}$ \\
\hline $\begin{array}{l}\text { Prescription rate for antibiotics } \\
\text { (unconditional on prescription) }\end{array}$ & $\begin{array}{c}0.633 \\
{[0.063]}\end{array}$ & $\begin{array}{c}0.5 \\
{[0.065]}\end{array}$ & $\begin{array}{l}0.433^{\star} \\
{[0.064]}\end{array}$ & $\begin{array}{l}0.117^{\star} \\
{[0.042]}\end{array}$ & $\begin{array}{l}0.083^{\star} \\
{[0.036]}\end{array}$ \\
\hline $\begin{array}{l}\text { Prescription rate for antibiotics } \\
\text { (conditional on prescription) }\end{array}$ & $\begin{array}{c}0.644 \\
{[0.063]}\end{array}$ & $\begin{array}{c}0.5 \\
{[0.065]}\end{array}$ & $\begin{array}{l}0.448^{*} \\
{[0.066]}\end{array}$ & $\begin{array}{c}0.125^{\star} \\
{[0.045]}\end{array}$ & $\begin{array}{c}0.096^{*} \\
{[0.041]}\end{array}$ \\
\hline \multicolumn{6}{|c|}{ Panel B. Types of Drugs (Conditional on Prescription) } \\
\hline Number of drugs prescribed & $\begin{array}{c}2.492 \\
{[0.109]}\end{array}$ & $\begin{array}{c}2.333 \\
{[0.105]}\end{array}$ & $\begin{array}{c}2.207 \\
{[0.106]}\end{array}$ & $\begin{array}{l}1.875^{\star} \\
{[0.081]}\end{array}$ & $\begin{array}{l}1.615^{\star} \\
{[0.092]}\end{array}$ \\
\hline Two or more types of drugs prescribed & $\begin{array}{c}0.932 \\
{[0.033]}\end{array}$ & $\begin{array}{c}0.867 \\
{[0.044]}\end{array}$ & $\begin{array}{c}0.828 \\
{[0.050]}\end{array}$ & $\begin{array}{l}0.750^{\star} \\
{[0.058]}\end{array}$ & $\begin{array}{l}0.519^{\star} \\
{[0.070]}\end{array}$ \\
\hline Prescription for Grade 1 antibiotics & $\begin{array}{c}0.492 \\
{[0.066]}\end{array}$ & $\begin{array}{c}0.383 \\
{[0.063]}\end{array}$ & $\begin{array}{c}0.414 \\
{[0.065]}\end{array}$ & $\begin{array}{c}0.125^{\star} \\
{[0.045]}\end{array}$ & $\begin{array}{l}0.096^{*} \\
{[0.041]}\end{array}$ \\
\hline Prescription for Grade 2 antibiotics & $\begin{array}{c}0.153 \\
{[0.047]}\end{array}$ & $\begin{array}{c}0.117 \\
{[0.042]}\end{array}$ & $\begin{array}{c}0.034^{*} \\
{[0.024]}\end{array}$ & $\begin{array}{l}0.000^{*} \\
{[0.000]}\end{array}$ & $\begin{array}{c}0.000^{\star} \\
{[0.000]}\end{array}$ \\
\hline \multicolumn{6}{|l|}{ Panel C. Drug Expenditures } \\
\hline $\begin{array}{l}\text { Total drug expenditure in RMB } \\
\text { (unconditional on prescription) } \\
\text { Total drug expenditure in RMB } \\
\text { (conditional on prescription) } \\
\end{array}$ & $\begin{array}{c}104.652 \\
{[7.141]} \\
106.426 \\
{[7.036]} \\
\end{array}$ & $\begin{array}{l}82.885^{\star} \\
{[6.094]} \\
82.885^{\star} \\
{[6.094]} \\
\end{array}$ & $\begin{array}{l}71.076^{\star} \\
{[5.715]} \\
73.526^{\star} \\
{[5.640]} \\
\end{array}$ & $\begin{array}{l}38.302^{\star} \\
{[2.984]} \\
41.038^{\star} \\
{[2.862]} \\
\end{array}$ & $\begin{array}{l}30.553^{\star} \\
{[3.930]} \\
35.253^{\star} \\
{[4.167]} \\
\end{array}$ \\
\hline \multicolumn{6}{|c|}{ Panel D. Service Quality Before Intervention } \\
\hline $\begin{array}{l}\text { Physician/nurse takes patient's } \\
\text { temperature }\end{array}$ & $\begin{array}{c}0.083 \\
{[0.036]}\end{array}$ & $\begin{array}{c}0.083 \\
{[0.036]}\end{array}$ & $\begin{array}{c}0.133 \\
{[0.044]}\end{array}$ & $\begin{array}{c}0.083 \\
{[0.036]}\end{array}$ & $\begin{array}{c}0.1 \\
{[0.039]}\end{array}$ \\
\hline Physician asks patient about sputum & $\begin{array}{c}0.5 \\
{[0.065]}\end{array}$ & $\begin{array}{c}0.55 \\
{[0.065]}\end{array}$ & $\begin{array}{c}0.533 \\
{[0.065]}\end{array}$ & $\begin{array}{c}0.433 \\
{[0.064]}\end{array}$ & $\begin{array}{c}0.483 \\
{[0.065]}\end{array}$ \\
\hline Physician uses a stethoscope & $\begin{array}{c}0.317 \\
{[0.061]}\end{array}$ & $\begin{array}{c}0.483 \\
{[0.065]}\end{array}$ & $\begin{array}{c}0.4 \\
{[0.064]} \\
\end{array}$ & $\begin{array}{c}0.333 \\
{[0.061]}\end{array}$ & $\begin{array}{c}0.333 \\
{[0.061]}\end{array}$ \\
\hline \multicolumn{6}{|c|}{ Panel E. Service Quality After Intervention, Unconditional on Prescription } \\
\hline $\begin{array}{l}\text { Physician voluntarily suggests drinking } \\
\text { more water etc. }\end{array}$ & $\begin{array}{c}0.633 \\
{[0.063]}\end{array}$ & $\begin{array}{l}0.817^{\star} \\
{[0.050]}\end{array}$ & $\begin{array}{c}0.583 \\
{[0.064]}\end{array}$ & $\begin{array}{l}0.433^{*} \\
{[0.064]}\end{array}$ & $\begin{array}{l}0.400^{*} \\
{[0.064]}\end{array}$ \\
\hline $\begin{array}{l}\text { Physician responds politely after being } \\
\text { thanked }\end{array}$ & $\begin{array}{c}0.8 \\
{[0.052]}\end{array}$ & $\begin{array}{c}0.867 \\
{[0.044]}\end{array}$ & $\begin{array}{l}0.617^{*} \\
{[0.063]}\end{array}$ & $\begin{array}{l}0.450^{\star} \\
{[0.065]}\end{array}$ & $\begin{array}{l}0.400^{\star} \\
{[0.064]}\end{array}$ \\
\hline Treatment Duration (min) & $\begin{array}{c}4.65 \\
{[0.359]}\end{array}$ & $\begin{array}{c}4.758 \\
{[0.204]}\end{array}$ & $\begin{array}{c}4.483 \\
{[0.311]}\end{array}$ & $\begin{array}{c}4.017 \\
{[0.294]}\end{array}$ & $\begin{array}{c}3.967 \\
{[0.272]}\end{array}$ \\
\hline $\begin{array}{l}\text { Patient's would recommend physician to } \\
\text { own parents (1-10: lowest-highest) }\end{array}$ & $\begin{array}{c}5.9 \\
{[0.319]}\end{array}$ & $\begin{array}{l}7.267^{*} \\
{[0.134]} \\
\end{array}$ & $\begin{array}{c}5.25 \\
{[0.273]} \\
\end{array}$ & $\begin{array}{l}4.750^{*} \\
{[0.215]}\end{array}$ & $\begin{array}{l}4.667^{*} \\
{[0.201]}\end{array}$ \\
\hline \multicolumn{6}{|c|}{ Panel F. Service Quality After Intervention, Conditional on Prescription } \\
\hline Physician asks about allergies & $\begin{array}{c}0.508 \\
{[0.066]}\end{array}$ & $\begin{array}{c}0.583 \\
{[0.064]}\end{array}$ & $\begin{array}{c}0.586 \\
{[0.065]}\end{array}$ & $\begin{array}{c}0.5 \\
{[0.067]}\end{array}$ & $\begin{array}{c}0.519 \\
{[0.070]}\end{array}$ \\
\hline Physician instructs on drug usage & $\begin{array}{c}0.322 \\
{[0.061]}\end{array}$ & $\begin{array}{c}0.45 \\
{[0.065]}\end{array}$ & $\begin{array}{c}0.414 \\
{[0.065]}\end{array}$ & $\begin{array}{l}0.000^{*} \\
{[0.000]}\end{array}$ & $\begin{array}{l}0.000^{\star} \\
{[0.000]}\end{array}$ \\
\hline $\begin{array}{l}\text { Physician voluntarily informs patient } \\
\text { of drug side effects }\end{array}$ & $\begin{array}{c}0.051 \\
{[0.029]}\end{array}$ & $\begin{array}{c}0.15 \\
{[0.047]}\end{array}$ & $\begin{array}{c}0.121 \\
{[0.043]}\end{array}$ & $\begin{array}{c}0 \\
{[0.000]}\end{array}$ & $\left.\begin{array}{c}0 \\
{[0.000]}\end{array}\right]$ \\
\hline
\end{tabular}

Notes: Standard deviations are in brackets. An asterisk indicates that the difference between the baseline and the treatment is significant at the $95 \%$ level of confidence. 
Table 6: Antibiotics Prescription

\begin{tabular}{|c|c|c|c|c|c|c|c|}
\hline \multirow[b]{2}{*}{ Independent Variable } & iable: & \multicolumn{3}{|c|}{ Antibiotics Prescription } & \multirow{2}{*}{$\begin{array}{l}\text { Two or } \\
\text { More } \\
\text { Types of } \\
\text { Drugs } \\
\quad(5) \\
\end{array}$} & \multirow{2}{*}{$\begin{array}{l}\text { Grade } 2 \\
\text { Prescribed } \\
\\
(6)\end{array}$} & \multirow{2}{*}{$\begin{array}{l}\text { Drug Exp. } \\
\text { In RMB } \\
\text { (7) }\end{array}$} \\
\hline & $(1)$ & $(2)$ & $(3)$ & $(4)$ & & & \\
\hline \multirow{2}{*}{ Gift Giving } & -0.13 & -0.13 & -0.14 & $-0.15^{\star}$ & -0.05 & -0.04 & $-23.52^{*}$ \\
\hline & {$[0.078]$} & [0.078] & [0.071] & [0.072] & [0.071] & [0.044] & [7.520] \\
\hline \multirow[t]{2}{*}{ Display } & $-0.20 \star$ & $-0.17^{\star}$ & $-0.18^{\star}$ & $-0.19^{*}$ & $-0.16^{\star}$ & $-0.13^{\star}$ & $-33.18^{*}$ \\
\hline & [0.078] & [0.078] & [0.071] & [0.071] & {$[0.070]$} & [0.043] & [7.468] \\
\hline \multirow[t]{2}{*}{ No Purchase } & $-0.52^{\star}$ & $-0.50 \star$ & $-0.50^{\star}$ & $-0.52^{\star}$ & $-0.25^{\star}$ & $-0.16^{\star}$ & $-65.53^{*}$ \\
\hline & {$[0.078]$} & {$[0.078]$} & [0.071] & {$[0.071]$} & {$[0.070]$} & [0.043] & {$[7.446]$} \\
\hline \multirow[t]{2}{*}{ Display * No Purchase } & 0.17 & 0.13 & 0.12 & 0.13 & -0.1 & 0.11 & $22.49 *$ \\
\hline & [0.111] & [0.114] & [0.104] & [0.105] & [0.103] & [0.064] & [10.951] \\
\hline \multirow[t]{2}{*}{ Doctor's Age: 31-40 } & & 0.08 & -0.03 & -0.05 & 0.08 & 0.01 & -3.57 \\
\hline & & [0.187] & [0.194] & [0.195] & [0.191] & [0.118] & [20.380] \\
\hline \multirow[t]{2}{*}{ Doctor's Age: 41-50 } & & 0.14 & 0.02 & -0.02 & 0.13 & 0.04 & 6.77 \\
\hline & & [0.189] & [0.195] & [0.197] & [0.193] & [0.120] & [20.614] \\
\hline \multirow[t]{2}{*}{ Doctor's Age: >=51 } & & 0.13 & 0.06 & 0.03 & 0.22 & 0.06 & 20.8 \\
\hline & & [0.190] & [0.213] & [0.215] & [0.211] & [0.131] & [22.469] \\
\hline \multirow[t]{2}{*}{ Doctor is Male } & & 0.04 & 0.05 & 0.04 & 0.1 & 0.02 & -0.18 \\
\hline & & [0.050] & [0.076] & {$[0.076]$} & {$[0.075]$} & [0.046] & [7.993] \\
\hline \multirow[t]{2}{*}{ Patient is Male } & & $0.13^{\star}$ & 0.06 & & & & \\
\hline & & [0.051] & [0.049] & & & & \\
\hline \multirow[t]{2}{*}{ Constant } & $0.63^{*}$ & $0.51^{*}$ & $0.63^{*}$ & $0.63^{*}$ & $0.93^{\star}$ & 0.15 & $104.64^{*}$ \\
\hline & {$[0.055]$} & [0.206] & [0.290] & {$[0.278]$} & [0.289] & [0.165] & [26.951] \\
\hline Observations & 300 & 300 & 300 & 300 & 300 & 300 & 300 \\
\hline R-squared & 0.21 & 0.25 & 0.51 & 0.55 & 0.48 & 0.33 & 0.55 \\
\hline Control variables & & $\sqrt{ }$ & $\sqrt{ }$ & $\sqrt{ }$ & $\sqrt{ }$ & $\sqrt{ }$ & $\sqrt{ }$ \\
\hline Hospital fixed effects & & & $\sqrt{ }$ & $\sqrt{ }$ & $\sqrt{ }$ & $\sqrt{ }$ & $\sqrt{ }$ \\
\hline Patient fixed effects & & & & $\sqrt{ }$ & $\sqrt{ }$ & $\sqrt{ }$ & $\sqrt{ }$ \\
\hline
\end{tabular}

Notes: Standard errors are in brackets. An asterisk indicates significance at the $95 \%$ level of confidence. 
Table 7: Service Quality Unconditional on Prescription

\begin{tabular}{|c|c|c|c|c|c|}
\hline \multirow[b]{2}{*}{ Dependent Variable } & \multicolumn{3}{|c|}{ Before Intervention } & \multicolumn{2}{|c|}{ After Intervention } \\
\hline & $\begin{array}{l}\text { Physician or } \\
\text { nurse takes } \\
\text { patient's } \\
\text { temperature }\end{array}$ & $\begin{array}{l}\text { Physician } \\
\text { asks about } \\
\text { sputum }\end{array}$ & $\begin{array}{l}\text { Physician } \\
\text { uses a } \\
\text { stethoscope }\end{array}$ & $\begin{array}{l}\text { Physician } \\
\text { suggests } \\
\text { drinking more } \\
\text { water etc. }\end{array}$ & $\begin{array}{l}\text { Physician } \\
\text { responds } \\
\text { politely after } \\
\text { being } \\
\text { thanked }\end{array}$ \\
\hline Independent Variable & (1) & (2) & (3) & (4) & (5) \\
\hline \multirow[t]{2}{*}{ Gift Giving } & 0.01 & 0.07 & $0.20^{*}$ & $0.19 *$ & 0.06 \\
\hline & {$[0.057]$} & [0.096] & [0.089] & [0.088] & {$[0.080]$} \\
\hline \multirow[t]{2}{*}{ Display } & 0.06 & 0.04 & 0.11 & -0.03 & $-0.18 *$ \\
\hline & {$[0.057]$} & [0.095] & [0.088] & [0.088] & [0.080] \\
\hline \multirow[t]{2}{*}{ No Purchase } & 0.01 & -0.05 & 0.04 & $-0.19 *$ & $-0.35^{\star}$ \\
\hline & {$[0.057]$} & [0.095] & [0.088] & [0.088] & [0.080] \\
\hline \multirow[t]{2}{*}{ Display*No Purchase } & -0.05 & -0.03 & -0.15 & 0.02 & 0.15 \\
\hline & [0.083] & [0.140] & [0.129] & [0.129] & {$[0.117]$} \\
\hline \multirow[t]{2}{*}{ Constant } & 0.08 & 0.5 & 0.32 & 0.63 & $0.80^{*}$ \\
\hline & [0.202] & [0.385] & [0.358] & {$[0.345]$} & [0.296] \\
\hline \multirow[t]{2}{*}{ R-squared } & 0.25 & 0.26 & 0.33 & 0.36 & 0.45 \\
\hline & \multicolumn{5}{|c|}{ After Intervention } \\
\hline \multirow[t]{2}{*}{ Dependent Variable } & $\begin{array}{l}\text { Visit Duration } \\
\text { (min) }\end{array}$ & $\begin{array}{l}\text { Patient would } \\
\text { recommend } \\
\text { physician } \\
(1-10)\end{array}$ & $\begin{array}{l}\text { Physician } \\
\text { asks about } \\
\text { drug allergies }\end{array}$ & $\begin{array}{l}\text { Physician } \\
\text { instructs on } \\
\text { drug usage }\end{array}$ & $\begin{array}{l}\text { Physician } \\
\text { informs about } \\
\text { side effects }\end{array}$ \\
\hline & $(6)$ & $(7)$ & $(8)$ & $(9)$ & $(10)$ \\
\hline \multirow[t]{2}{*}{ Gift Giving } & 0.06 & $1.45^{\star}$ & 0.04 & 0.11 & $0.11^{*}$ \\
\hline & [0.408] & {$[0.347]$} & {$[0.097]$} & {$[0.075]$} & {$[0.047]$} \\
\hline \multirow[t]{2}{*}{ Display } & -0.26 & -0.57 & 0.05 & 0.11 & 0.08 \\
\hline & [0.406] & {$[0.344]$} & {$[0.097]$} & {$[0.075]$} & {$[0.047]$} \\
\hline \multirow[t]{2}{*}{ No Purchase } & -0.69 & $-1.13^{\star}$ & -0.04 & $-0.32^{*}$ & -0.06 \\
\hline & [0.404] & [0.343] & [0.099] & {$[0.076]$} & {$[0.047]$} \\
\hline \multirow[t]{2}{*}{ Display*No Purchase } & 0.1 & 0.52 & 0.05 & -0.09 & -0.04 \\
\hline & [0.595] & [0.505] & [0.146] & [0.112] & {$[0.070]$} \\
\hline \multirow[t]{2}{*}{ Constant } & $4.64^{*}$ & $5.90^{\star}$ & 0.51 & 0.32 & 0.05 \\
\hline & [1.589] & [1.403] & [0.383] & [0.318] & [0.208] \\
\hline R-squared & 0.35 & 0.43 & 0.27 & 0.43 & 0.32 \\
\hline Control Variables & $\sqrt{ }$ & $\sqrt{ }$ & $\sqrt{ }$ & $\sqrt{ }$ & $\sqrt{ }$ \\
\hline Hospital fixed effects & $\sqrt{ }$ & $\sqrt{ }$ & $\sqrt{ }$ & $\sqrt{ }$ & $\sqrt{ }$ \\
\hline Patient fixed effects & $\sqrt{ }$ & $\sqrt{ }$ & $\sqrt{ }$ & $\sqrt{ }$ & $\sqrt{ }$ \\
\hline
\end{tabular}

Notes: There are 300 observations. Standard errors are in brackets.

Columns 8-10 show estimates conditional on a drug being prescribed.

An asterisk indicates significance at the $95 \%$ level of confidence. 


\section{APPENDIX: FIELD EXPERIMENT PROTOCOL I. INTRODUCTION}

The audit studies described in this protocol were conducted between October 2011 and January 2012, during the flu season. The basic design of an audit study involves sending testers who follow a prescribed script to the people who are being audited. All of our testers presented with a set of vague cold/flu-like symptoms which are described in the script appended to this protocol. They did not ask for antibiotics or any other particular treatment.

Sections II and III describe the way in which hospitals and students were selected. Section IV describes how students were trained to play the role of a simulated patient. Section V describes how students were assigned to hospitals and doctors. Section VI provides transcripts of the physician visits. Section VII describes how testers were asked to evaluate their visits. Lastly, Section VIII describes how we collected further data about the medicines prescribed.

\section{HOSPITAL SELECTION}

We restricted our sample to large general public hospitals as they are more likely to have more than two physicians in the respiratory department, and our auditors were less likely to be conspicuous in a hospital with a large volume of patients. We randomly choose 40 large tertiary hospitals out of the 48 tertiary hospitals in Beijing and 20 hospitals from the 52 secondary hospitals. In China, non-urgent care patients typically present at the department that they expect to be seen in. We made appointments for our patients with doctors in the department of respiratory medicine 
at these hospitals as described further below.

\section{STUDENT SELECTION}

We recruited students by advertising in collegiate online forums (i.e. BBS), offering monetary compensation of 50 RMB per doctor visit (about 7 U.S. Dollars). To ensure that students had time to conduct the experiment, in the advertisement we indicated that students interested in participating should have at least three-half days available without any class or other obligations. A total of 42 students sent an email indicating their interest in participating.

We met with the 42 students as a group and explained that the experiment involved students going to hospitals to see doctors for flu-like conditions. Four students were uncomfortable going to hospitals, and left. Of the remaining 38 students, we selected students with no history of rhinitis or any other upper respiratory tract infection to ensure that the physical condition of the students would not affect the results. After further matching students based on their physical appearance, we chose 15 students to participate in the study and grouped them into 3 groups of 5 students each. All of our students were 21 years old in their junior year.

\section{STUDENT TRAINING}

At the beginning of the training process, all students were asked to sign a pledge of confidentiality. They then underwent 9 hours of group instruction and individual practice to standardize their performance and appearance. During the training, they not only learnt the purpose and the design of the study, but also received instructions 
on the transcript and how to behave, dress, etc. We also instructed students that if they exhibited any symptoms of sickness, they would be asked to stop the experiment until they fully recovered and no longer showed signs of sickness.

To ensure that they did not speak too fast or too slow all students were instructed to take about 15 seconds to give the chief complaint (about 31 Chinese words). Additionally, students were given a patient evaluation questionnaire which they were required to complete after each visit. The questionnaire covers the questions physicians asked (whether the physician asked about coughing, sputum, allergies), examinations the physician performed (took temperature, checked tonsils, used a stethoscope), and the level of care provided to patients (informed patient of drug sideeffects, instructed on drug usage, suggested drinking more water, responded politely after being thanked) and finally the circumstances of visit (number of other physicians/patients in the office, number of patients in the waiting areas). To ensure they could fill out the after-experiment survey properly, students were required to memorize all the questions in the survey.

After the instructions, students were separated into pairs and they practiced their memorized transcripts via role-play (i.e. one student played the role of the "physician" while the other played the role of the "patient"). Finally, each student practiced with one of the principal investigators (Dr. Lin) individually, as a check on whether the student had memorized the transcript. If anything was wrong in the practice, the student was requested to keep practicing until he or she performed adequately.

To ensure that simulated patients were well trained, before the actual 
implementation of the audit study, simulated patients conducted the experiment twice in a primary hospital. Upon completion of the two practice visits, students were required to show that they could bring back prescriptions and fill out the evaluation questionnaire. If the two practice visits were carried out successfully, then we considered students ready to go.

\section{ARRANGING VISITS}

We created a table with the following information for each simulated patient: Visit Order, Visit Date, Role Played, Hospital ID and Physician ID (See Table 2). In each visit, the patient's role and his or her visit order was randomly assigned. Appointments were made before the visit, in conformity with the patient's visit order. All patients except the one in role D (display of knowledge and the indication that the patient will purchase the drugs elsewhere) see the same doctor. Patient D visits another physician in the same hospital. Appointments were made with doctors in the respiratory medicine group at the hospitals. While Chinese students have health care available on campus, they are not insured if they go off campus. At the registration window, the hospitals were told that the simulated patients did not have insurance.

\section{PHYSICIAN-VISITING PROCEDURES}

\section{Gift-giving Procedures}

If a gift is to be given, it is given immediately upon meeting the doctor (See Appendix Figure 1 for the gift). Patient $A_{\text {gift }}$ says: "I have a pen here. It is useful and pretty. Please feel free to take it." If the physician does not accept, simulated patient 


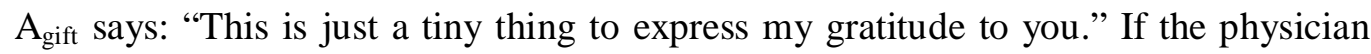
still insists on not accepting the gift, Patient $\mathrm{A}_{\text {gift }}$ says: "That's all right." And then the simulated patient takes the gift back.

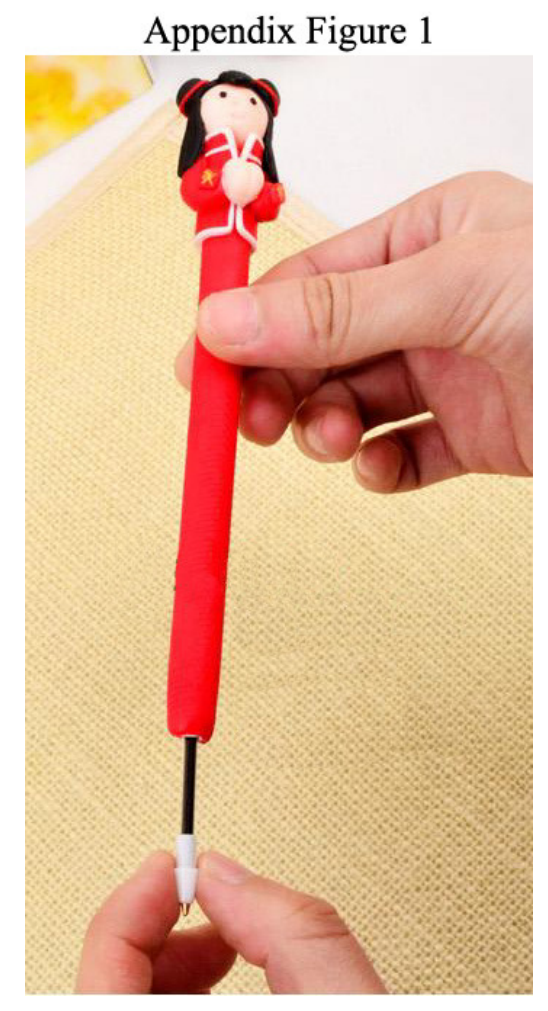

\section{Statement of the Chief Complaint}

1. Hello, doctor!

2. For the last two days, I've been feeling fatigued. I have been having a low grade fever, slight dizziness, a sore throat, and a poor appetite. This morning, the symptoms worsened so I took my body temperature. It was $37^{\circ} \mathrm{C}$.

3. If simulated patients are asked questions about symptoms mentioned in the chief complaint, they are supposed to answer appropriately. If the doctor asks about other symptoms not in the chief complaint, then they should say that there are no such symptoms.

4. Answer $\mathrm{NO}$ if asked the following questions:

Do you feel nauseous? 
Do you have any phlegm?

Do you have any muscle soreness?

Have you eaten anything bad or unclean recently?

Are you currently taking any medications?

Do you have medicine at home?

\section{Physical Examination}

Physician: I'll give you a physical examination/I will now conduct a physical exam. After the physical examination, patient B says "I learned from the internet that simple

flu/cold patients should not take antibiotics. Is this true? Can I not take antibiotics unless they are necessary?"

Patient $\boldsymbol{C}$ says: "Doctor, my sister-in-law works at a drug store. She can offer me a discount if I buy drugs in her store. But I don't know what medicine to take, so could you please write prescription for me?"

Patient D says both what Patient B says and what Patient C says.

The doctor might ask some additional questions as follows:

Physician: What kind of drug store? /what kind of drugs are there in the store?

Patient: A big store. I guess it has all drugs I need.

(If the physician does not want to prescribe)

Patient: I need the prescription to buy medicine in the drug store. Would you please give me some advice?

(If that does not work)

Patient: I don't know the medicine at all. Please write me a prescription, thank you.

Patient: I am not familiar with the drugs. Please help prescribe the medicine.

\section{Physician's Diagnoses and Explanation of Findings}


Physician: I'll prescribe [...] for you.

Patient: Okay. (ask the physician for information regarding side effects of the medicine after 3-4 seconds if the physician does not voluntarily inform you of the side effects).

\section{Departure}

Patient: Thank you! (Make sure to bring prescriptions with you as you leave).

Physician: You are welcome.

\section{PATIENT EVALUATION}

On the same day as the hospital visits, simulated patients were asked to evaluate their visit according to the following questionnaire and submit it to the principal investigator (Dr. Lin).

\section{Physician Information Collection}

(Note that the only information retained about physicians was their gender, and their approximate age).

1: What was the gender of the physician?

(1) Male (2) Female

2: What was the approximate age of the physician?
(1) 30 or below
(2) $31-40$
(3) $41-50$
(4) above 50

3A: Did the physician share the office with other physicians?

3B: If yes, how many physicians shared the office?

4: While you were waiting to see the doctor, how many other patients were waiting with you in the waiting areas?

5: On average, how much time did the patient(s) before you spend with the doctor (minutes per patient)?

6: When you entered the physician's office, were there other patients in the office as well? If yes, how many? 
7: Did the physician ask whether or not you have cough symptoms?

8: Did the physician ask whether or not you have sputum?

\section{Physical Examination}

9: Did the physician/nurse take your temperature?

10A: Did the physician examine your tonsils?

10B: If yes, did the physician give you some information about the examination results?

11A: Did the physician use a stethoscope?

11B: If yes, did the physician give you some information about the examination results?

\section{Physicians Diagnose and Explain Findings}

12: Did the physician ask you whether you have a history of allergies?

13: Did the physician ask you whether you have cold medicine at home?

14A: Did the physician prescribe medication(s)?

14B: If yes, did the physician take initiative in giving instructions on drug usage? (i.e. before meals, after meals, how many times a day, how many pills a time, etc.)

$14 \mathrm{C}$ : If yes, did the physician take initiative in telling you the side effects of the medicine?

15: Did the physician take initiative in telling you to pay attention to certain things? (i.e. drink more, have more rest, wear warm cloths, eat more fruit, or avoid strenuous activity etc).

\section{Departure}

16: After you said "Thank you, doctor," did the physician respond to you with polite words like "You are welcome", etc?

\section{Satisfaction Appraisement for Physician (scores)}


Lastly, simulated patients evaluated the service they received from each physician. Service and degree of satisfaction were rated on a scale of 1 to 10 (low to high).

17: How considerate was your physician during your hospital visit?

18: How would you rate the medical professional ability of your doctor?

19: How respectful was the physician of your opinions during the diagnosing process?

20: Do you think the physician offered you enough information about your treatment and illness?

21: Overall, how was your experience?

22: Would you recommend this physician to your parents, given that they presented with the same symptoms?

23: What was the treatment duration of your visiting? (in minutes)

\section{PRESCRIPTION ANALYSIS}

All the simulated patients were asked to turn their prescriptions over to two research assistants from School of Medicine, Peking University. By analyzing these prescriptions, the research assistants obtained the following information:

1: The total number of drugs prescribed.

2: Whether antibiotics were prescribed.

3: If yes, the level of antibiotic prescribed.

4: The cost of the drugs prescribed.

Costs were determined as follows. If the physician did not prescribe, then the drug expenditure was zero. If drugs were prescribed, expenditures were calculated in one of three ways: In $78 \%$ of all cases, the cost of the drug(s) was already listed on the prescription, so we could calculate the drug expenditure directly. In $7 \%$ of the cases, patients obtained total drug costs from the hospital pharmacy. In $2 \%$ of the cases, 
students obtained the drug price simply by looking at the physician's computer screen while the physician filled out the prescription. In the remaining $13 \%$, we found the prices either on the website of the local Price Bureau, or through online search engines, Google and Baidu. After being analyzed, the prescriptions were destroyed since they could be used to identify hospitals and physicians. 